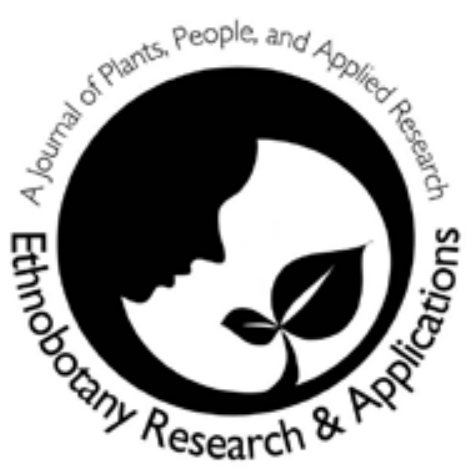

\title{
Ethnobotanical Knowledge of Men, Women and Children in Rural Niger: A mixed- methods approach
}

\author{
Iro Dan Guimbo, Jocelyn Muller \& Mahamane Larwanou
}

\section{Research}

\begin{abstract}
Ethnobotanical studies often underestimate or misrepresent impacts of age and gender on individual ethnobotanical knowledge. This paper compares two common methodologies, participant observation and key-informant interviews, to examine the variation of ethnobotanical knowledge across age and gender in three communities in rural southwest Niger. We compared lists of plants mentioned in interviews as food, fodder, construction and medicine, to lists compiled from observations of daily activities. Compared to men, women reported more edible plants, different medicinal plants, and less detailed information on construction plants. Interview data indicated ethnobotanical knowledge increased with age. However, in observations youth ate a greater diversity of food plants and identified and ranked fodder species more quickly than adults. This paper supports previous research on age and gender effects on ethnobotanical knowledge and critiques common research methods and assumptions. We advocate for mixed-method approaches to gather more nuanced understandings of ethnobotanical knowledge.
\end{abstract}

\section{Résumé}

Les études, souvent sous-estiment ou présentent mal les impacts de l'âge et du genre sur la connaissance ethnobotanique individuelle. Cet article compare deux méthodes: l'observation et l'interview afin d'examiner la variation de la connaissance ethnobotanique en fonction de l'âge et du genre dans trois communautés rurales du sud-ouest du Niger. Nous avons comparé les listes des plantes utilisées dans l'alimentation, le fourrage, la construction et la pharmacopée, à l'issue de l'interview aux listes établies sur la base des observations d'activités quotidiennes.
Comparé aux hommes, les femmes connaissent mieux les plantes comestibles et celles utilisées dans la pharmacopée et ont moins de connaissance sur les plantes utilisées dans la construction. Les données d'interview ont montré que la connaissance ethnobotanique évolue avec l'âge. Cependant, d'après les observations, les jeunes consomment une grande diversité des plantes alimentaires, identifient et classent les espèces fourragères plus rapidement que les adultes. Cet article vient confirmer les résultats des recherches antérieures sur l'influence de l'âge et du genre dans les connaissances ethnobotaniques et critique les méthodes de recherches courantes et les suppositions. Nous préconisons les approches mixtes pour appréhender les nuances sur les connaissances ethnobotaniques.

\section{Background}

There is an underlying assumption in much ethnobotanical research that traditional knowledge increases with age

\section{Correspondence}

Iro Dan Guimbo, Forestry Department, Agriculture Faculty, Abdou Moumouni University, Niamey, NIGER.

Danguimbo@yahoo.fr

Jocelyn Muller, Department of Biology, Tufts University, Medford, Massachussetts, U.S.A.

jocelyn.muller@tufts.edu

Mahamane Larwanou, Forestry Department, Agriculture Faculty, Abdou Moumouni University, Niamey, NIGER.

M.Larwanou@CGIAR.ORG

Ethnobotany Research \& Applications 9:235-242 (2011)

Published: May 25, 2011 
and or duration of residence in a region or habitat (Davis \& Wagner 2003). Thus to maximize research time and resources, researchers often prefer to work with a select number of key informants who are the oldest or longest term residents in an area (Pfeiffer \& Butz 2005). Although recent reviews see this pattern as changing, it is still common (Reyes-Garcia et al. 2006b).

This method of sampling has several potential limitations, especially in cultures with strong gender segregation and age defined roles. Pfeiffer and Butz (2005) argued that this type of selective sampling can have an unintended gender bias, favoring the gender which does not move with marriage as the "longer-term" residents. Such gender or age-biased sampling can underestimate the extent of ethnobotanical variation within communities (Zweifel 1997). Conversely such studies may over-estimate the importance of species typically used by older residents. In the course of conservation efforts that require community level support, this bias can also lead to a false impression of the species value and either over- or under-estimate the extent of resource harvest.

The data presented in this paper stems from a community level survey of the ethnobotanical knowledge of local natural resource needs and botanical conservation priorities of three villages in the département (state) of Boboye in southwest Niger: Boumba, Djabou, and Gongueye (Figure 1). In order to avoid the aforementioned biases, the participants were selected to include a cross-section of community members representative of local gender, age and ethnicity diversity. In the course of this study, we uncovered interesting patterns in both age and gender variation, which reinforced the need for stratified designs and mixed methods approaches. This paper attempts to highlight these unexpected patterns of ethnobotanical knowledge across age, gender and method used. We present the results of two commonly used methods of sampling local knowledge- semi-structured interviews and participant observation - and evaluate the ability of such methods to

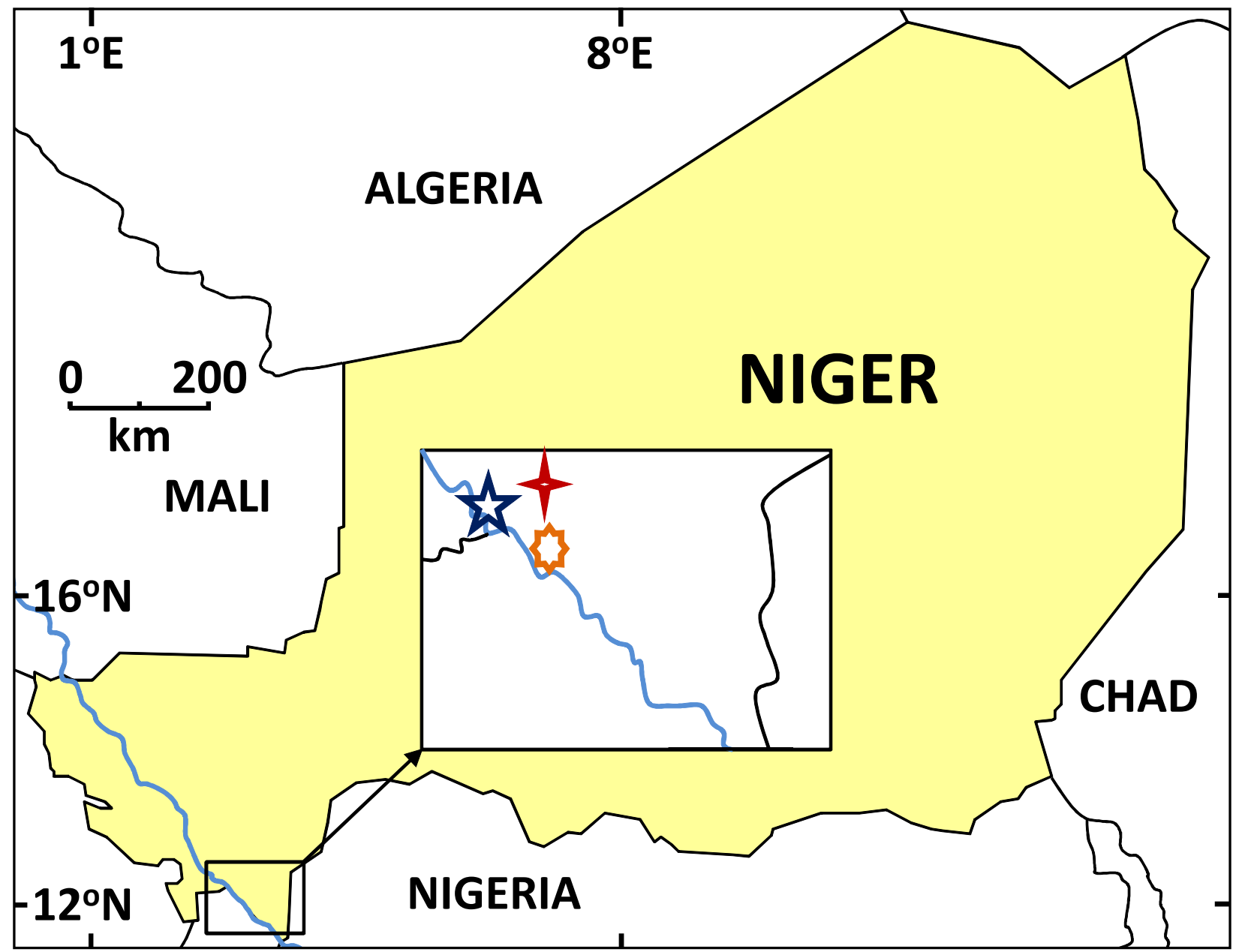

Figure 1. The study area located in département of Boboye, southwest Niger. The enlarged region shows the placement of the three towns participating in the study: Boumba (5-point star), Gongeye (4-point star and Djaboukiria (8-point star). The blue line that runs along through the enlarged area and along the border is the River Niger. 


\section{Dan Guimbo et al. - Ethnobotanical Knowledge of Men, Women and Children 237 in Rural Niger: A mixed-methods approach}

capture this variation in the context of three communities in south-west Niger.

\section{Methods}

This paper is based on field research conducted by the first author, while living in Boumba, Niger (N12 24.665 , E2 ${ }^{\circ}$ 50.247) from August - October 2006. This semi-arid region is characterized by marginal agriculture and herding (BaiduForson \& Renard 1996, Wickens 1997), which require most community members to depend on a range of natural resources to support, supplement and diversify their livelihoods (Assogbadjo et al. 2008, Glew \& Vanderjagt 2006; Humphry et al. 1993, Muller \& Dan Guimbo 2008). Religious laws and cultural norms common to this region serve to define distinct gender and age segregated spaces, identities, and duties within each of these villages (Muller 2007). The objective of this study was to survey ethnobotanical knowledge. Based on previous research and a familiarity with cultural norms, we began this survey with the assumptions that: 1) knowledge will increase with increase with age; 2) Women would have a greater knowledge of food plants, and; 3) Men would have a greater knowledge of fodder and construction plants.

The bulk of the data was collected from semi-structured key informant interviews, which allowed for some probing of incomplete answers while minimizing the variability between responses. All interviews were conducted orally by the first author, Dan Guimbo, (a native Hausa speaker from the Maradi region) either in Hausa or in Zarma with the assistance of a local translator. Question guides were written by Dan Guimbo in a context and language that was to be understood by residents of the area. These guides focused on two themes: which species were useful; how these useful species managed. For this paper we focus only on which plants were listed, or the first half of the interviews. The question guides were tested in a pilot study in Boumba with both men and women individually and with a group of men. After the pilot study, questions were adjusted to improve of comprehension, cultural acceptance, and the objectives of the study.

Full interviews were conducted with a sample of 16 heads of household, 14 women, and 10 youth (girls and boys) in each village. Male participants were nominated by the chef de village or chef de quartier (village/ neighborhood leader), chosen to represent the inherent variability of socioeconomic status, ethnicity, and education. The results of the interviews were then analyzed across gender and age separately to look at the number and type of species listed in each of four use-categories - food, fodder, construction, and medicinal plants - which were relevant to our a priori expectations of the knowledge of gender and age knowledge patterns. For each socio-ecological group, we calculated both the mean and total number of plants listed and then looked at the amount of overlap plant names reported between groups.
In this paper we do not explore the effect of ethnicity, but included ethnic diversity as a part of the sampling strategy. All three villages were predominately Zarma villages containing minority populations of Fulani and Hausa. Ethnic diversity of study participants was similar between all gender and age groups sampled and proportional to the community make up.

After conducting the interviews the first and second authors participated in the daily activities of men, women, and children, specifically observing which plants were being used, who collected the plants for their use and what methods of collection were employed. The first author alternately accompanied men, women, and children to fields, home gardens and bush lands and participated in field activities and the collection of food, fodder and medicinal species. Since the first author was only residing in the village from August to October, his participant observation was limited to activities during the rainy season or cultivation season. Additionally, cultural norms dictated that he could not accompany young women alone. To balance these limitations we included observations made by the second author during the dry season and in working with women during four years of fieldwork in the region. When reviewing and analyzing field notes for this study we aimed to ensure an equal number of observations from each group and compare them to observations made in different years and seasons We looked specifically at numbers of plants gathered by men, women and children and their ecological awareness of the species-how easily a desired plant was found, recognition of different life stages and growth habits.

Opportunistic discussion, group discussion of the results of the interviews, discussions with local conservation technicians, and market surveys all conducted by the first and second authors served to assist in the interpretation and contextualization of the results. Voucher specimens were collected for the purposes of expert identification and deposited at the Abdou Moumouni University in Niamey [Herbier, Laboratoire de Biologie Végétale, École des Sciences de Niamey, Niamey, Niger (ESN)]. This research was conducted with the permission of the Nigerien ministry of secondary education and with the oral consent of all village leaders and interview participants and conforms to international ethical research standards, such as the declaration of Helsinki.

\section{Results}

In individual and group interviews women $(n=14)$ listed both on average (women $=19.81$, men $=13.54$ ) and in total $($ women $=28$, men $=21)$ a greater number of species of edible plants than men $(n=16)$. Women also were better able to recognize and name edible plants in the field. At the same time certain plants such as Trianthema portulacastrum L. and Portulaca oleracea L. harvested for their 


\section{Plants Listed in Interviews in Rural Niger}

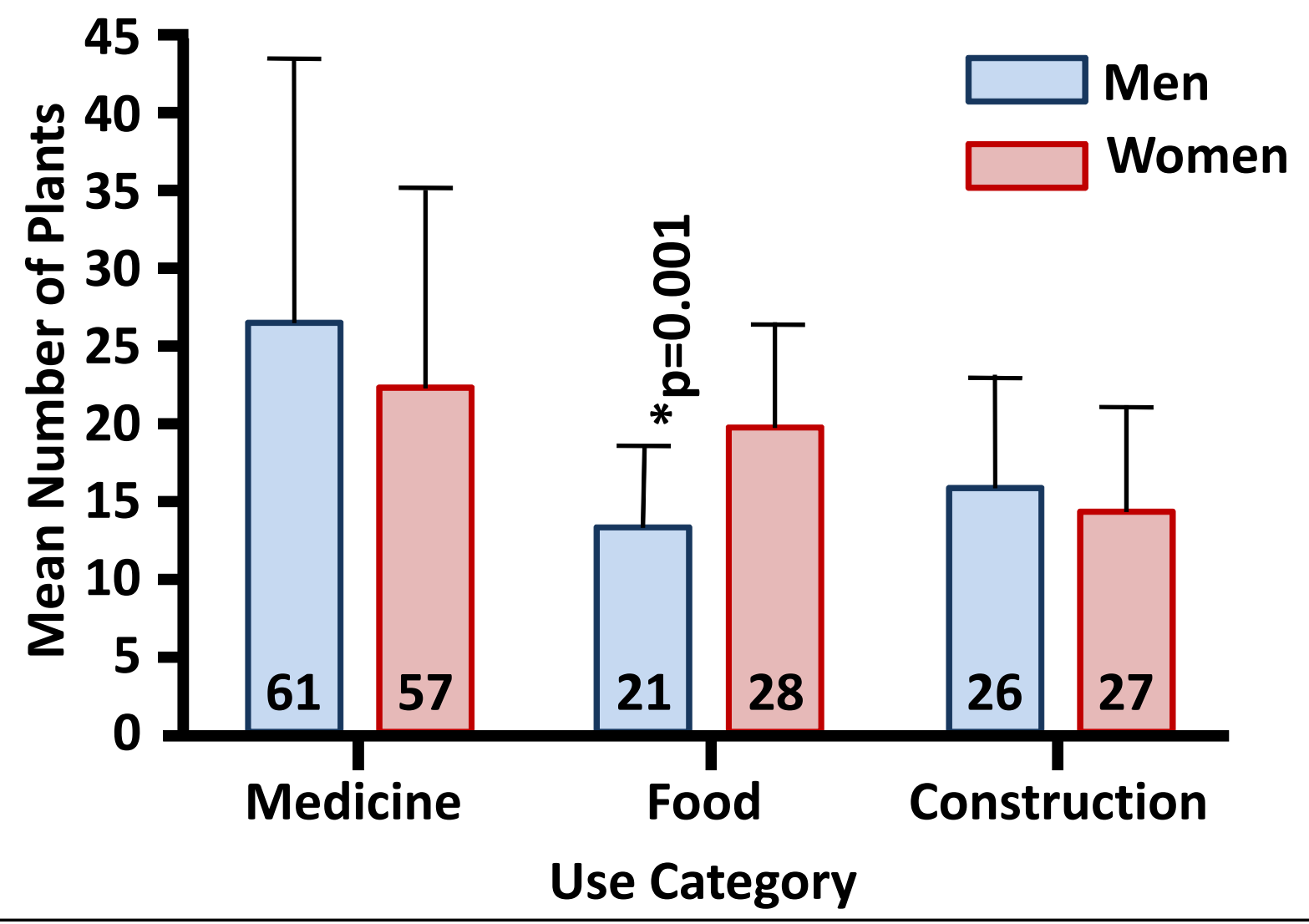

Figure 2. Ethnobotanical Knowledge across Gender. Average number of plants listed by male and female participants of all ages for three different use categories (medicine, food and construction). Lists were generated in individual interviews and the bars represent the mean number of plants listed (+ SEM). The number on the bars represent the cumulative total number of plants listed by youth or adult participants for each category. The average number of plants listed for medicine and construction did not differ significantly, however on average women listed significantly more food plants than men (GLM, df=1, $F=30.58, P=0.0001)$.

edible greens would be confused by male participants, but were readily identified and classified by women.

Interestingly, women also listed more species used for construction (Figure 2), although men demonstrated a more detailed knowledge of the plants they reported, listing not only names of species used, but also each species' ability to resist termites and decay, its market price, and average life span. In the field, it was observed that although women could list more names of construction plants, men had more consistent identification of these grasses. For example, women would often confuse three important construction grasses with similar morphology, (Cymbopogon giganteus Chiov., Hyperthelia dissoluta (Nees ex Steud.) Clayton and Andropogon gayanus Kunth), whereas most male participants could distinguish among these same grasses, including early plant growth stage and post harvest.
There was also a difference in how plants were generally collected by men and women. Women would go in search of large quantities of firewood, or edible plants one day before market day. Additionally, women were observed in the course of field labours opportunistically collecting food plants and firewood to bring back to the homestead. Many of these plants had been weeded and discarded by male farmers. In contrast, men harvested plant products for food and construction systematically in large quantities, much in the same way as cultivated plants. Generally only fodder was observed to be collected by men in small daily rations alongside other activities.

The average and total number of medicinal plants listed by men and women did not differ significantly (Figure 2 ). The two lists of medicinal plants did differ in content with only $30 \%$ of the species contained by both (data not shown). Women's lists of medicinal plants begin with, and often exclusively contain, plants used for jiti or a tradi- 


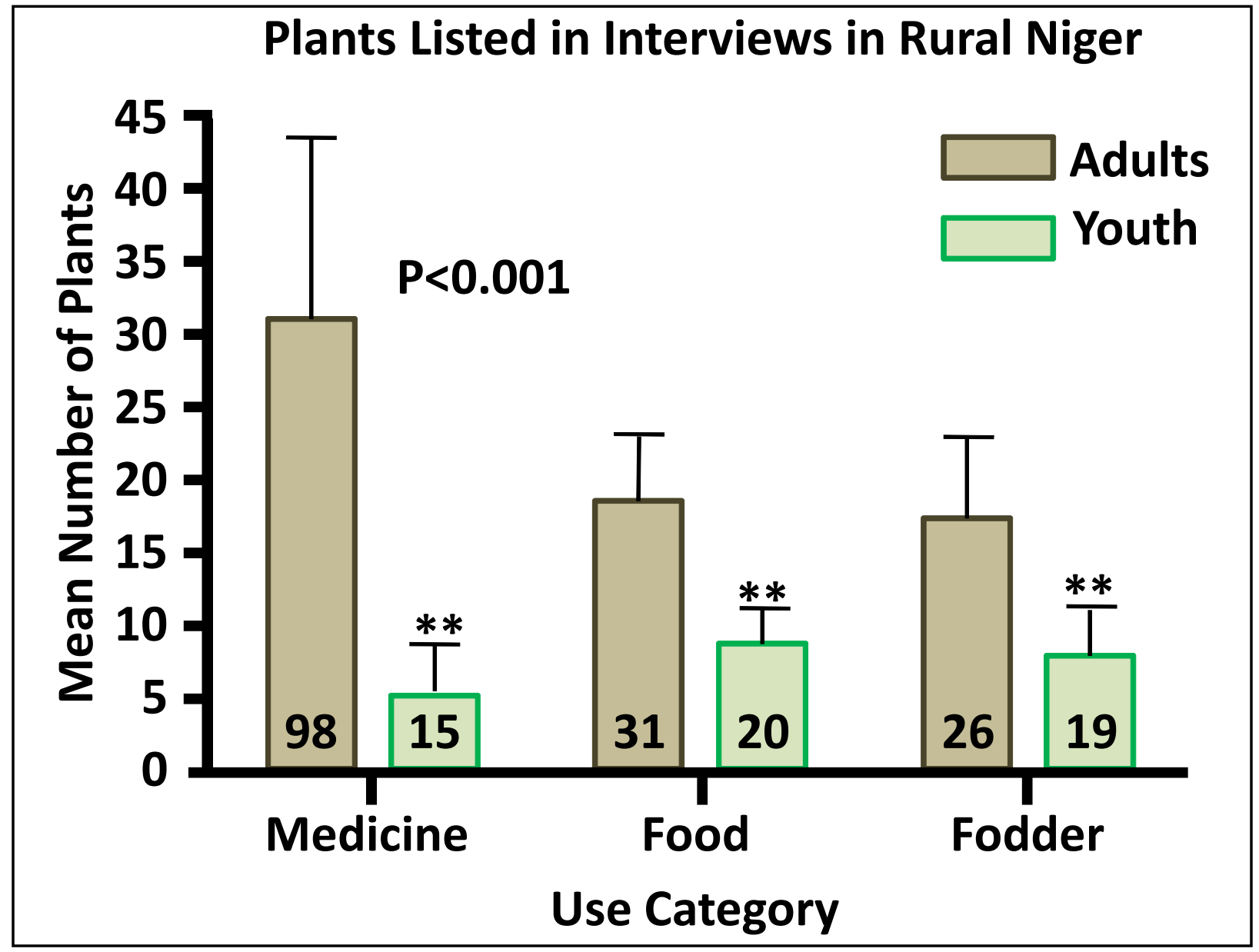

Figure 3. Ethnobotanical Knowledge between adults and youth. Average number of plants listed by adult and youth participants of both genders for three different use categories (medicine, food and fodder). Lists were generated in individual interviews and the bars represent the mean number of plants listed (+ SEM). Youth participants listed significantly fewer plants on average than adult participants (GLM, df $=1, \mathrm{~F}$ 's $>24.34, \mathrm{P}$ 's $<0.0001)$. The number on the bars represent the cumulative total number of plants listed by youth or adult participants for each category.

tional medicine used to wash and protect newborns and infants, or plants used during pregnancy or lactation. Due to the preventative nature of these remedies, the level of harvest was often much higher than observed for other medicinal plants cited by men. Observations showed that every newborn regardless of health is washed in a jiti infusion, and given small amounts to drink. This practice of washing continued generally until children approached weaning.

In interviews, children listed fewer species than adults for all use categories (Figure 3), and generally were only able to name, describe and discuss fruit and food plants. There were no plants that children were able to name that were not already named by older participants. However, further engagement with the community challenged that perspective. In the course of participant observation, children were observed to identify and qualitatively select preferred fod- der species. Younger participants demonstrated an extensive knowledge of fodder species simply in the course of their daily activities. Although they often had difficulty naming a plant, children were able to say quickly and correctly identify which animal will eat or prefer which plant, often better than their parents. Furthermore, if engaged in discussion or games many youth displayed greater precision in generating lists of which plants are eaten by which animals. Children were routinely sent for collection of animal fodder, or to tend the animals in the pastures, with little parental guidance. Boys aged seven to twelve often sold fodder grasses in the market, generally for their own pocket money. They selected pasture and fodder based on their own observations of animal behavior, discussions with their peers, or their own knowledge base. Additionally, children ate and gathered a greater diversity of food plants than they reported in interviews. Children were observed to gather a greater diversity of food plants than 
adults did. However, younger participants rarely collected or reported names of medicinal plants and rare plants.

\section{Discussion}

Examining the interview data, the age and gender-based patterns of ethnobotanical knowledge were very distinct. The patterns observed supported our hypotheses and previous studies in this region and elsewhere. We saw a greater command of ethnobotanical knowledge with increased age (Figure 3), whereas lists generated by men and women differed both by number and quality or type, indicating distinct spheres of knowledge.

As women in this region bear most of the burden of daily food production, they also were able to list more edible plants than men. Women recognized, collected, and prepared a greater diversity of food plants than men, both in interviews and as observed on a daily basis. And the converse was true for fodder plants, where men reported, recognized and utilized more fodder plants than female participants. These results supported our hypotheses and matched expectations based on Phillips and Gentry's (1993) proposition that knowledge increases not only with age but also with frequent application of that knowledge.

Following that same logic, we expected men to have a greater knowledge of fodder and construction plants, which they used more frequently. We observed men in this region regularly gathering most large construction materials such as thatch, timber and rope fibres. Most information women reported was acquired second-hand. As expected men were able to provide more detailed information about the construction materials they listed. However, although the information women provided was less detailed, the lists were longer and often included rare or historical construction materials. This supports Pfeiffer and Butz (2005) argument that broad generalizations cannot be made regarding which gender is most likely to report particular resources and every effort should be made to always have gender-balanced sampling. Perhaps distance from the activity, which many participant women had, can allow individuals the freedom to think of more rarely used resources.

Age also affected the use of and familiarity with natural resources. Analysis based only on the interview and listing exercises seemed to support the traditional assumption that ethnobotanical knowledge increases with age, and that studies based only on data from the older residents would be sufficient to describe the community natural resource use as a whole. However, the results from participant observation put into question how ethnobotanical knowledge is measured and tools used to assess children's knowledge. Children in this study often did not know the names of plants, which they used and understood ecologically. Listing names is simply not a good measure of the botanical knowledge of these children. In these three towns, children tend to learn through observation and participation, which may explain why they know the plant but not its name. Conversely, although women could list the same number of plants used for construction as men, their knowledge was less detailed and often second-hand. In the field women often confused thatch grasses with similar uses and morphologies and rarely could list additional information regarding the ecology or conservation of these species, or compare and contrast different species with great detail. In this case women knew the names of the plants, but not the plant. As children were learning fodder species in the field by watching sheep eat, women were learning about construction grasses through household conversation rather than practice. The first group knew too few names to properly asses their botanical knowledge through interviews or free lists, the latter too many. These results underscore the limits of the use of plant names as a tool to measure botanical knowledge and point to the necessity of multiple methods to contextualize and validate ethnobotanical information and assessments.

In the case of medicinal plants, it is not a question of who reported more or less, plants, but a case of gendered domains of knowledge within medicine. Women and men reported very different sets of medicinal plants with little overlap. A study based on male key informants alone would overlook key medicinal plants used by women for the practice of jiti, underestimate medicinal plant harvest and undervalue the potential importance of ethnobotanical knowledge of the mother or female relatives to child health and nutrition. These results confirmed the importance of inclusion gender and other drivers of heterogeneity in ethnobotanical studies (Camou-Guerrero et al. 2008, Dalle \& Potvin 2004, Ghimire et al. 2004, Pfeiffer \& Butz 2005).

Finally, the variation in results between method question the assumption that ethnobotanical knowledge simply increases with age. The results did clearly support that the knowledge of plant names increased with age. However, in the case of some use categories, such as animal fodder, youth were observed to hold a more detailed ecological knowledge than their knowledge of names would suggest. Our results indicated similar results as found by Phillips and Gentry (1993) on construction woods, however, these results would have been overlooked if relying on plant names and interviews alone. Since older participants in this study spend less time tending the animals than the younger participants, they may have forgotten some of the details of animal foraging and feeding from their youth. Alternatively, this might also indicate changing socio-economic realities similar to findings such as in Voeks (2007) study on women in Brazil. The majority of the participants were subsistence farmers, for whom tending animals is a relatively recent cultural phenomenon that arose with the diversification of household survival strat- 


\section{Dan Guimbo et al. - Ethnobotanical Knowledge of Men, Women and Children 241 in Rural Niger: A mixed-methods approach}

egies in the last 30 years. Many adults in this region of Niger, have had less direct experience observing animal feeding behavior as have their children, and therefore have less detailed knowledge about the plants used for forage and fodder.

\section{Conclusions}

This is a small study with limitations in collection methods and sample size, so although these results cannot make great claims on the patterns of ethnobotanical knowledge everywhere, they do provide points of reflection regarding the process of collecting data. With these notes we hope to challenge common methods and assumptions of ethnobotanical studies. Traditional knowledge is not a homogeneous community - owned resource. Gender and age patterns resulted in heterogeneous patterns of botanical resource use, knowledge and value within the community (Camou-Guerrero et al. 2008, DeWalt et al. 1999, Pfeiffer \& Butz 2005, Reyes-Garcia et al. 2006a, Voeks 2007, Zarger \& Stepp 2004). However, the patterns of knowledge in this study, like those illuminated by Pfeiffer and Butz (2005), were more nuanced than is often described in the literature and cannot be assumed to simply follow stereotypical gender or age lines. Secondly, these results advocate for the mixed-method approaches to understanding cultural knowledge put forth by authors in the participatory research field (Almedom et al. 1997, Chambers 1992, 2007, Lawrence et al. 2005). Even using a small sample of interviews, by contrasting the interview data with participant observation we were able to uncover and question the patterns of knowledge especially across age groups. We would argue as Almedom et al did, that the interviews should help to refine and target the participant observation, improving the quality and efficacy of that data collection (1997). Finally, these results advocate for the need to increase the diversity of participants in key informant sampling methods to include a cross-section of sub-populations that co-exist within a community. In this study we focused on gender and age, but ethnicity (Ræbild et al. 2007), economic class (Pilgrim et al. 2008), religion (Reichel 1999) and education (Voeks \& Leony 2004) are all factors which vary within most communities and may influence how people perceive, use, and value natural resources, and therefore sway the outcomes of conservation efforts as well as other community level actions.

\section{Acknowledgements}

We thank Lt. Abdoullaye Soumana, Baba Tanda and other park staff at the Boumba government post. We thank Hassan Kobia, Malan Harouna and the late Chef de Village de Boumba and other village leaders from Boumba, Gongeye and Djabou for their assistance in translation, identifying informants and hosting. We thank the communities in Gongeye, Boumba and Djabou for their participa- tion and welcome. The participation of the second author in the field was facilitated by the Switzer Foundation and a NSF graduate research fellowship.

\section{Literature Cited}

Almedom, A.M., U. Blumenthal \& L. Manderson. 1997. Hygiene Evaluation Procedures: Approaches and methods for assessing water and sanitation related hygiene practices. International Nutrition Foundation for Developing Countries, Boston, Massachusetts.

Assogbadjo, A.E., R. Glélé Kakai, F.J. Chadare, L. Thomson, T. Kyndt, B. Sinsin \& P. Van Damme. 2008. Folk classification, perception, and preferences of baobab products in west africa: Consequences for species conservation and improvement. Economic Botany 62:74-84.

BaiduForson, J. \& C. Renard. 1996. Comparing productivity of millet-based cropping systems in unstable environments of the sahel: Possibilities and challenges. Agricultural Systems 51:85-95.

Camou-Guerrero, A., V. Reyes-García, M. Martínez-Ramos \& A. Casas. 2008. Knowledge and use value of plant species in a rarámuri community: A gender perspective for conservation. Human Ecology 36:259-272.

Chambers, R. 1992. Rural appraisal: Rapid, relaxed and participatory. University of Sussex, Institute of Development Studies, Brighton, U.K.

Chambers, R. 2007. From PRA to PLA to pluralism: Practice and theory. IDS Working Paper 286. University of Sussex, Institute of Development Studies, Brighton, U.K.

Dalle, S.P. \& C. Potvin. 2004. Conservation of useful plants: An evaluation of local priorities from two indigenous communities in eastern panama. Economic Botany 58:38-57.

Dan Guimbo, I., M. Saadou \& M. Larwanou. 2007. Patterns of Botanical Resource Use in Three Rural Villages in Southwest Niger. Paper presented at 48th Meeting of the Society for Economic Botany, Chicago, Illinois, June 9th.

Davis, A. \& J. Wagner. 2003. Who knows? On the importance of identifying "experts" when researching local ecological knowledge. Human Ecology 31:463-489.

DeWalt, S.J., G. Bourdy, L.R. Chávez De Michel \& C. Quenevo. 1999. Ethnobotany of the tacana: Quantitative inventories of two permanent plots of northwestern bolivia. Economic Botany 53:237-260.

Ghimire, S., D. McKey \& Y. Aumeeruddy-Thomas. 2004. Heterogeneity in ethnoecological knowledge and man- 
agement of medicinal plants in the himalayas of nepal: Implications for conservation. Ecology and Society 9:6.

Glew, R.S. \& D. Vanderjagt. 2006. Coping strategies and nutritional health in rural niger: Recommendations for consumption of wild plant foods in the sahel. International Journal of Food Sciences and Nutrition 57:314-324.

Humphry, C.M., M.S. Clegg, C.L. Keen \& L.E. Grivetti. 1993. Food diversity and drought survival. The Hausa example. International Journal of Food Sciences and Nutrition 44:1-16.

Lawrence, A., O.L. Phillips, A.R. Ismodes, M. Lopez, S. Rose, D. Wood \& A.J. Farfan. 2005. Local values for harvested forest plants in Madre de Dios, Peru: Towards a more contextualised interpretation of quantitative ethnobotanical data. Biodiversity and Conservation 14:45-79.

Muller, J. 2007. Seeking women's participation in ethnoecological fieldwork. Journal of Ecological Anthropology 13:64-8.

Muller, J. \& I. Dan Guimbo. 2008. Eats shoots and leaves: Adding local understanding to the discussion of famine food resources in niger. Practicing Anthropology 30:2932.

Pfeiffer, J.M. \& R.J. Butz. 2005. Assessing cultural and ecological variation in ethnobiological research: The importance of gender. Journal of Ethnobiology 25:240.

Phillips, O. \& A.H. Gentry. 1993. The useful plants of Tambopata, Peru .2. Additional hypothesis-testing in quantitative ethnobotany. Economic Botany 47:33-43.

Pilgrim, S.E., L.C. Cullen, D.J. Smith \& J. Pretty. 2008. Ecological knowledge is lost in wealthier communities and countries. Environmental Science and Technology 42:1004-1009.
Ræbild, A., H.H. Hansen, J. Dartell, J.M.K. Ky \& L. Sanou. 2007. Ethnicity, land use and woody vegetation: A case study from south-western Burkina Faso. Agroforestry Systems 70:157-167.

Reichel, E. 1999. Cosmology, worldview and genderbased knowledge systems among the Tanimuka and Yukuna (northwest Amazon). World Views: Environment, Culture, Religion 3:213-242.

Reyes-Garcia, V., T. Huanca, V. Vadez, W. Leonard \& D. Wilkie. 2006a. Cultural, practical, and economic value of wild plants: A quantitative study in the bolivian amazon. Economic Botany 60:62-74.

Reyes-Garcia, V., V. Vadez, S. Tanner, T. Huanca, W. Leonard \& T. McDade. 2006b. Measuring what people know about the environment. A review of quantitative studies. Journal of Ethnobiology 27:182-203.

Voeks, R.A. 2007. Are women reservoirs of traditional plant knowledge? Gender, ethnobotany and globalization in northeast brazil. Singapore Journal of Tropical Geography 28:7-20.

Voeks, R.A. \& A. Leony. 2004. Forgetting the forest: Assessing medicinal plant erosion in eastern Brazil. Economic Botany 58:S294-S306.

Wickens, G.E. 1997. Has the sahel a future? Journal of Arid Environments 37:649-663.

Zarger, R.K. \& J.R. Stepp. 2004. Persistence of botanical knowledge among Tzeltal Maya children. Current Anthropology 45:413-418.

Zweifel, H. 1997. The gendered nature of biodiversity conservation. National Women's Studies Association Journal 9(3):107-123. 